Elena Yu. Bragina ${ }^{1}$ / Irina A. Goncharova ${ }^{1}$ / Anna F. Garaeva ${ }^{1,2}$ / Evgeniy V. Nemerov ${ }^{2}$ / Anastasija A. Babovskaya ${ }^{2}$ / Andrey B. Karpov ${ }^{3}$ / Yulia V. Semenova ${ }^{4}$ / Irina Z. Zhalsanova' / Densema E. Comboeva ${ }^{1}$ / Olga V. Saik ${ }^{5}$ / Olga I. Zolotareva ${ }^{6,7}$ / Vladimir A. Ivanisenko ${ }^{5}$ / Victor E. Dosenko ${ }^{8} /$ Ralf Hofestaedt $^{6}$ / Maxim B. Freidin'

\title{
Molecular Relationships between Bronchial Asthma and Hypertension as Comorbid Diseases
}

\footnotetext{
${ }^{1}$ Research Institute of Medical Cenetics, Tomsk NRMC, Tomsk, Russia, E-mail: elena.bragina72@gmail.com. https://orcid.org/0000-0002-1103-3073, https://orcid.org/0000-0002-9527-7015, https://orcid.org/0000-0002-1439-6259.

${ }^{2}$ Siberian State Medical University, Tomsk, Russia

${ }^{3}$ Seversk Biophysical Research Centre of the Federal Medico-Biological Agency, Seversk, Russia

${ }^{4}$ Seversk Clinical Hospital, Siberian Federal Research and Clinical Centre of the Federal Medico-Biological Agency, Seversk, Russia

${ }^{5}$ The Federal Research Center Institute of Cytology and Cenetics, The Siberian Branch of the Russian Academy of Sciences, Novosibirsk, Russia

${ }^{6}$ Bielefeld University, Bioinformatics/Medical Informatics Department, Bielefeld, Germany. https://orcid.org/0000-0002-9424-8052.

7 International Research Training Group "Computational Methods for the Analysis of the Diversity and Dynamics of Cenomes" and Genome Informatics, Faculty of Technology and Center for Biotechnology, Bielefeld University, Bielefeld, Germany. https://orcid.org/0000-0002-9424-8052.

${ }^{8}$ Bogomoletz Institute of Physiology, National Academy of Science, Kiev, Ukraine
}

\begin{abstract}
:
Comorbidity, a co-incidence of several disorders in an individual, is a common phenomenon. Their development is governed by multiple factors, including genetic variation. The current study was set up to look at associations between isolated and comorbid diseases of bronchial asthma and hypertension, on one hand, and single nucleotide polymorphisms associated with regulation of gene expression (eQTL), on the other hand. A total of 96 eQTL SNPs were genotyped in 587 Russian individuals. Bronchial asthma alone was found to be associated with rs1927914 (TLR4), rs1928298 (intergenic variant), and rs1980616 (SERPINA1); hypertension alone was found to be associated with rs11065987 (intergenic variant); rs2284033 (IL2RB), rs11191582 (NT5C2), and rs11669386 (CARD8); comorbidity between asthma and hypertension was found to be associated with rs1010461 (ANG/RNASE4), rs7038716, rs7026297 (LOC105376244), rs7025144 (intergenic variant), and rs2022318 (intergenic variant). The results suggest that genetic background of comorbidity of asthma and hypertension is different from genetic backgrounds of both diseases manifesting isolated.
\end{abstract}

Keywords: Comorbidity, Bronchial Asthma, Hypertension, eQTL, SNP

DOI: $10.1515 /$ jib-2018-0052

Received: July 26, 2018; Revised: October 12, 2018; Accepted: November 13, 2018

\section{Introduction}

Epidemiological study provide evidence that some diseases tend to develop together more often that it would be expected by chance, suggesting shared pathogenetic mechanisms [1]. Various terms are used to describe this phenomenon, such as co-morbidity, syntropy, multi-morbidity. Examples of common comorbid diseases include allergic disorders (bronchial asthma, allergic rhinitis, atopic dermatitis) [2], autoimmune phenotypes of so-called "the kaleidoscope of autoimmunity" [3], cardiovascular diseases continuum [4].

Importantly, such combinations are common not only in an individual, but in their relatives, thus implying hereditary factors presented by pleiotropic, co-regulated syntropic genes involved in shared pathways [5].

Bronchial asthma, a common disease of airways, is often co-morbid with cardiovascular disorders [6], [7], [8], especially in women [9], and late-onset patients [10]; however, the increased rates of hypertension in asthma patients are observed in the vast majority of the studied populations [11]. 
Mechanisms underlying this common co-morbidity remain unknown. Among the discussed reasons of the development of hypertension in asthma patients are the decrease of lung function, systemic inflammation, impairment of smooth muscle tonus regulation, vascular remodelling, adverse effects of therapy, as well as genetic factors [12].

Systems biology provides ground for understanding molecular basis of pathogenesis of co-morbid diseases and offers novel view on diseases classification. Rzhetsky et al. built a phenotypic network of diseases including 657 using $1.5 \mathrm{mln}$ clinical records based on the co-morbidity between the diseases [13]. Both positive and negative correlations between the diseases was identified, e.g. schizophrenia and bipolar disorder (positive correlation) or aorta aneurism and schizophrenia, breast cancer and bipolar disorder (negative correlations). Another approach that used both data on disorders and genes from OMIM catalogue allowed building a network of 867 diseases with genes associated with at least two disorders [14]. Protein interaction networks can also be used to determine molecular causes of co-morbidity [15].

We hypothesise that co-morbidity between asthma and hypertension is largely based on underlying genetic variation. Recently, we used a bioinformatics approach to prioritise genes that are likely important for the comorbidity based on the analysis of associative networks [16]. To provide further support for the hypothesis, in the current study we set out to carry out the analysis of association between asthma, hypertension and their comorbidity and functional SNPs linked to variation in gene expression (eQTL) for the genes established in the previous study.

\section{Materials and Methods}

\subsection{Study Groups}

A total of 587 individuals from West Siberia (Tomsk Region, Russia) were studied (Table 1). Participants were included in the study in case they were not related to each other and were of self-reported European ancestry. Recruitment was carried out in clinical facilities of the city of Tomsk and the city of Seversk. Diagnoses of bronchial asthma and essential hypertension were defined based on clinical and laboratory investigations of the participants in accordance with WHO accepted criteria. All patients with arterial hypertension exhibited not clinical or laboratory symptoms and signs of secondary hypertension. Individuals with the presence of systemic complex diseases such as type 1 diabetes; obesity III-IV degree and cancer were excluded from analysis. Control group comprised healthy individuals with normal arterial blood pressure and without bronchial asthma.

Table 1: Characteristics of the study groups.

\begin{tabular}{|c|c|c|c|}
\hline \multirow[t]{2}{*}{ Group } & \multirow[t]{2}{*}{ Sample size (\%) } & \multicolumn{2}{|c|}{ Age, years } \\
\hline & & mean $\pm S D$ & range \\
\hline Hypertension & 144 & $44.9 \pm 8.9$ & $39-60$ \\
\hline Males & $97(67.4 \%)$ & & \\
\hline Females & $47(32.6 \%)$ & & \\
\hline Asthma & 145 & $44.9 \pm 8.9$ & $28-68$ \\
\hline Males & $39(26.9 \%)$ & & \\
\hline Females & $106(73.1 \%)$ & & \\
\hline Hypertension+Asthma & 146 & $56.3 \pm 10.5$ & $26-75$ \\
\hline Males & $40(27.4 \%)$ & & \\
\hline Females & $106(72.6 \%)$ & & \\
\hline Control & 152 & $47.7 \pm 9.9$ & $31-74$ \\
\hline Males & $40(26.3 \%)$ & & \\
\hline Females & $112(73.7 \%)$ & & \\
\hline Total & 587 & & \\
\hline
\end{tabular}

SD, standard deviation.

The study was approved by the Bioethics Committee of the Research Institute of Medical Genetics; a full verbal explanation of the investigation was given and written informed consent was obtained from all participants. 


\subsection{Genetic Analyses}

Total genomic DNA was isolated from peripheral blood by phenol/chloroform extraction method. A total of 96 eQTL SNP were selected and genotyped by MALDI-TOF mass-spectrometry using Sequenom MassARRAY iPLEX (USA). Genotypes were established by automatic analysis using MassARRAY Typer 4 software.

\subsection{Statistical Analysis}

Statistical analysis was carried out in R programming environment. The analysis of associations between the SNPs and diseases was carried out using logistic regression adjusting for age and sex. Additive genetic model was tested. The Hardy-Weinberg equilibrium (HWE) was tested using Fisher's exact test. The significance threshold was set at $p<0.05$.

\section{Results and Discussion}

We studied association of eQTL SNPs of genes (TLR4, CAT, IL10, CST3, ICAM1, IRF6, AKT1, NFKB1, PNP, SELL, CCL5, IL2RB, IDS, FOS, NT5C2, BHLHE40 and etc.) selected by bioinformatics analysis [16] with bronchial asthma, hypertension and their combination. A total of 96 SNPs were studied. All of the SNPs met the expectations under HWE. For six SNPs (rs17350806, rs4987367, rs4743691, rs2284368, rs7548533, and rs4743692) genotyping rate was $<80 \%$; therefore, they were excluded from the analysis.

\subsection{Polymorphisms associated with bronchial asthma}

Three polymorphisms were found to be associated with isolated bronchial asthma (Table 2). Two of them (rs1927914 and rs1928298) are located in a proximity to TLR4 and are in strong LD ( $\left.\mathrm{r}^{2}=0.97\right)$ [17]. They influence TLR4 expression in various cell types including blood cells and oesophagus smooth muscles [18], [19], [20]. The gene encodes a pattern-recognition receptor essential in innate immunity by transducing microbial signals, such as LPS of gram-negative bacteria. The role of innate immunity in bronchial asthma pathogenesis is not fully understood; however, in patients with neutrophilic asthma, TLR4 along with related protein TLR2, are highly activated [21]. These receptors are also thought to be linked to fatal asthma exacerbations [22]. In the literature, there are data about the impact of TLR family genes polymorphisms on susceptibility to various phenotypes of bronchial asthma [23], [24], [25].

Table 2: Genotypes prevalence in the studied groups for polymorphisms nominally associated with at least one of the studied phenotypes.

\begin{tabular}{|c|c|c|c|c|c|}
\hline $\begin{array}{l}\text { SNP ID (localisation, } \\
\text { functional consequence) }\end{array}$ & Genotype & BA (\%) & Hypertension (\%) & BA+ Hypertension (\%) & Control (\%) \\
\hline \multirow{3}{*}{$\begin{array}{l}\text { rs1927914 (TLR4, upstream } \\
\text { variant) }\end{array}$} & AA & $51(35.7)$ & $62(43.4)$ & $75(51.7)$ & $75(51.4)$ \\
\hline & AG & $82(57.3)$ & $68(47.6)$ & $61(42.1)$ & $57(39.0)$ \\
\hline & GG & $10(7.0)$ & $13(9.0)$ & $9(6.2)$ & $14(9.6)$ \\
\hline$p$ & & 0.0397 & 0.5915 & 0.5571 & \\
\hline \multirow[t]{3}{*}{ rs1928298 (intergenic) } & TT & $52(37.4)$ & $61(43.9)$ & $73(52.5)$ & $74(51.1)$ \\
\hline & $\mathrm{TC}$ & $76(54.7)$ & $66(47.5)$ & $57(41.0)$ & $58(40.0)$ \\
\hline & $\mathrm{CC}$ & $11(7.9)$ & $12(8.6)$ & $9(6.5)$ & $13(8.9)$ \\
\hline$p$ & & 0.0442 & 0.7059 & 0.6119 & \\
\hline \multirow{3}{*}{$\begin{array}{l}\text { rs1980616 (SERPINA1, } \\
\text { intron variant) }\end{array}$} & $\mathrm{CC}$ & $96(67.1)$ & $80(56.3)$ & $83(57.2)$ & $82(56.9)$ \\
\hline & $\mathrm{CT}$ & $44(30.8)$ & $53(37.3)$ & $55(37.9)$ & $54(37.5)$ \\
\hline & TT & $3(2.1)$ & $9(6.3)$ & $7(4.8)$ & $8(5.6)$ \\
\hline$p$ & & 0.0462 & 0.7530 & 0.6592 & \\
\hline \multirow[t]{3}{*}{ rs11065987 (intergenic) } & AA & $51(36.2)$ & $54(38.8)$ & $42(29.2)$ & $47(31.5)$ \\
\hline & AG & $63(44.7)$ & $69(49.6)$ & $69(47.9)$ & $36(24.2)$ \\
\hline & GG & $27(19.1)$ & $16(11.5)$ & $33(22.9)$ & $66(44.3)$ \\
\hline$p$ & & 0.2922 & 0.0076 & 0.7872 & \\
\hline
\end{tabular}




\begin{tabular}{|c|c|c|c|c|c|}
\hline \multirow{3}{*}{$\begin{array}{l}\text { rs2284033 (IL2RB, intron } \\
\text { variant) }\end{array}$} & GG & $41(31.5)$ & $45(31.5)$ & $37(28.9)$ & $32(25.6)$ \\
\hline & GA & $57(43.8)$ & $53(37.1)$ & $56(43.8)$ & $51(40.8)$ \\
\hline & AA & $32(24.6)$ & $45(31.5)$ & $35(27.3)$ & $42(33.6)$ \\
\hline$p$ & & 0.1308 & 0.0359 & 0.3451 & \\
\hline \multirow{3}{*}{$\begin{array}{l}\text { rs11191582 (NT5C2, utr } \\
\text { variant } 5 \text { prime) }\end{array}$} & GG & $\begin{array}{r}114 \\
(80.3)\end{array}$ & $121(86.4)$ & $114(79.7)$ & $115(77.7)$ \\
\hline & GA & $28(19.7)$ & $19(13.6)$ & $27(18.9)$ & $33(22.3)$ \\
\hline & AA & $0(0.0)$ & $0(0.0)$ & $2(1.4)$ & $0(0.0)$ \\
\hline$p$ & & 0.6743 & 0.0419 & 0.6273 & \\
\hline \multirow{3}{*}{$\begin{array}{l}\text { rs11669386 (CARD8, intron } \\
\text { variant) }\end{array}$} & AA & $47(32.9)$ & $43(30.5)$ & $42(29.4)$ & $31(21.5)$ \\
\hline & AG & $65(45.5)$ & $73(51.8)$ & $65(45.5)$ & $78(54.2)$ \\
\hline & GG & $31(21.7)$ & $25(17.7)$ & $36(25.2)$ & $35(24.3)$ \\
\hline$p$ & & 0.0746 & 0.0433 & 0.7157 & \\
\hline \multirow{3}{*}{$\begin{array}{l}\text { rs1010461 (ANG/RNASE4, } \\
\text { intron variant) }\end{array}$} & AA & $41(28.5)$ & $57(40.1)$ & $57(39.3)$ & $43(29.1)$ \\
\hline & $\mathrm{AC}$ & $81(56.3)$ & $62(43.7)$ & $66(45.5)$ & $62(41.9)$ \\
\hline & $\mathrm{CC}$ & $22(15.3)$ & $23(16.2)$ & $22(15.2)$ & $43(29.1)$ \\
\hline$p$ & & 0.1346 & 0.0728 & 0.0024 & \\
\hline \multirow{3}{*}{$\begin{array}{l}\text { rs7038716 (LOC105376244, } \\
\text { nc transcript variant) }\end{array}$} & AA & $93(65.5)$ & $87(62.6)$ & $68(47.9)$ & $94(63.9)$ \\
\hline & AT & $46(32.4)$ & $42(30.2)$ & $66(46.5)$ & 46 (31.3) \\
\hline & TT & $3(2.1)$ & $10(7.2)$ & $8(5.6)$ & $7(4.8)$ \\
\hline$p$ & & 0.4580 & 0.9637 & 0.0113 & \\
\hline \multirow{3}{*}{$\begin{array}{l}\text { rs7026297 (LOC105376244, } \\
\text { upstream variant) }\end{array}$} & $\mathrm{CC}$ & $90(63.8)$ & $88(62.9)$ & $70(49.3)$ & $89(62.2)$ \\
\hline & $\mathrm{CT}$ & $47(33.3)$ & $42(30.0)$ & $65(45.8)$ & 47 (32.9) \\
\hline & TT & $4(2.8)$ & $10(7.1)$ & $7(4.9)$ & $7(4.9)$ \\
\hline$p$ & & 0.5023 & 0.8979 & 0.0299 & \\
\hline \multirow[t]{3}{*}{ rs7025144 (intergenic) } & $\mathrm{CC}$ & $86(60.6)$ & $89(62.7)$ & $70(48.6)$ & 89 (61.4) \\
\hline & $\mathrm{CT}$ & $52(36.6)$ & $45(31.7)$ & $67(46.5)$ & $49(33.8)$ \\
\hline & TT & $4(2.8)$ & $8(5.6)$ & $7(4.9)$ & $7(4.8)$ \\
\hline$p$ & & 0.7464 & 0.9369 & 0.0343 & \\
\hline \multirow[t]{3}{*}{ rs2022318 (intergenic) } & GG & $45(31.9)$ & $55(39.3)$ & $42(28.4)$ & $53(35.8)$ \\
\hline & GC & 75 (53.2) & $61(43.6)$ & $64(43.2)$ & $74(50.0)$ \\
\hline & $\mathrm{CC}$ & $21(14.9)$ & $24(17.1)$ & $42(28.4)$ & $21(14.2)$ \\
\hline$p$ & & 0.5132 & 0.8730 & 0.0444 & \\
\hline
\end{tabular}

$p-p$-value for additive model of association between disorders and SNPs; highlighted are $p$-values $<0.05$, the significance threshold in the current study; BA - bronchial asthma.

Another gene found to be associated with bronchial asthma in the current study, SERPINA1, encodes a serine protease inhibitor. The chromosomal region where the gene resides (14q32.13) is associated with the levels of IgE, bronchial hyperreactivity and other signs of allergic inflammation in different populations [26], [27], [28]. Gene expression profiling of epithelial cells stimulated by key allergy cytokines IL-4 and IL-13 showed most remarkable increase of expression of serpin family genes SERPINB3 и SERPINB4 [29]. Their role in the pathogenesis of bronchial asthma is not known, but they can exhibit protective effects via inhibiting endogenous proteases associated with inflammatory response.

\subsection{Polymorphisms associated with hypertension}

A polymorphism rs11065987 associated with hypertension in the current study have been found to be associated in genome-wide association studies (GWAS) with a number of phenotypes related to the risks of cardiovascular diseases, including lipid levels [30], [31] and BMI [32]. This variant is considered as the marker of the locus of susceptibility to ischemic stroke and ischemic heart disease [33].

Another variant associated with hypertension in the current study resides in IL2-receptor gene IL2RB, which takes part in T-cell mediated immune response. Previously, IL2RB gene expression was found to be correlated with diastolic blood pressure levels in a large sample of 7017 individuals [34].

The rs11191582 SNP associated with hypertension in the current study is located in the gene-reach region near CYP17A1-CNNM2-NT5C2. The region contains a remarkable number of regulatory SNPs associated with the development of cardiovascular disorders in GWAS studies [35]. The SNP rs11191582 is a cis-eQTL for NT5C2, USMG5, and hsa-mir-1307 genes that are abundantly expressed in the whole blood [18]. 
Another polymorphism associated with hypertension in the current study, rs11669386, is located in an intron of the caspase recruitment domain family member 8 gene (CARD8). The gene is involved in apoptosis, inflammation and NF-kappaB signaling. CARD8 along with NLRP3 controls activity of caspase-1 and is involved in caspase-1-mediated activation of IL-1 $\beta$ [36]. In turn, both caspase- 1 and IL-1 $\beta$ are crucial players in the development of coronary pathology in mouse model of Kawasaki disease [37].

\subsection{Polymorphisms associated with the comorbidity between bronchial asthma and hypertension}

The polymorphism rs1010461 associated with the comorbidity, is located in intron 1 of angiogenin gene (ANG) and is an eQTL for ANG and RNASE4 genes with shared promoter. The proteins encoded by ANG and RNASE4 genes have $38.7 \%$ similarity and belong to ribonuclease family (RNase). Their major function is induction of neovascularization [38]. Angiogenic activity of these genes may be important for interpretation of their associations with the comorbidity. Angiogenin is induced in inflammation and exhibit wound-healing effects and microbicide activity [39]. In patients with arterial hypertension, the decrease of angiogenin and fibroblasts growth factor levels is observed along with the increase of the levels of endostatin, vascular endothelial grown factor, and IL-8, suggesting a disbalance of pro-/anti-angiogenic factors in this condition [40]. Increased vascularisation promotes bronchial asthma pathogenesis and correlates with several signs of clinical course of the disease including bronchial hyperreactivity and airflow limitation [41]. The levels of angiogenin and vascular endothelial grown factor are increased during asthma exacerbation and decreased followed by corticosteroid treatment [42]. This raises a possibility that this is corticosteroid treatment that promotes the development of hypertension in genetically predisposed asthma patients.

The comorbidity between bronchial asthma and hypertension was associated with three SNPs known to be eQTLs for TLR4 gene according to GTEx database: two LD-bound polymorphisms rs7038716 and rs7026297 as well as intergenic rs7025144 SNP.

Finally, rs2022318 SNP, an eQTL for CAT gene was found to be associated with the comorbidity between asthma and hypertension. Catalase encoded by the gene is an important antioxidant enzyme preventing harmful effects of active oxygen species. As a result, polymorphisms of this gene are widely studied in diseases though to be linked with oxidative stress. Promoter SNPs for this gene were found to be associated with cardiometabolic diseases [43], [44], bronchial asthma [45], type 1 diabetes and other diseases [46].

\section{Conclusion}

The important observation from the current study is the difference in SNPs associated with isolated bronchial asthma and hypertension or their comorbidity, thus suggesting different genetic background of the comorbidity. On the other hand, considering associations of TLR4 SNPs, this gene variation may be important both for the development of isolated bronchial asthma and comorbidity of bronchial asthma and hypertension. The most pronounced impact on the development of comorbidity between bronchial asthma and hypertension can be attributed to the TLR4, CAT and ANG/RNASE4 genes, suggesting the importance of inflammation, neovascularisation, and oxidative stress in co-pathogenesis of both diseases. Importantly, according to our bioinformatics analysis, TLR4 and CAT genes have the highest priority in the development of bronchial asthma and hypertension comorbidity [16]. Consistently, we observed associations of these genes with the comorbidity, thus providing evidence for productivity in the use of bioinformatics approaches for the planning of human association studies.

Currently not enough of GWAS are published aimed at the study of comorbidity. These works aimed to study psychiatric diseases [47], [48]. Our study, unlike GWAS, focuses on specific SNPs of genes found using bioinformatics approaches that can cause comorbidity of asthma and hypertension.

This study has limitations, including no correction for multiple testing, small sample sizes, wide age range of the patients, and no correction for the use of therapy. Thus, the results of the current study must be treated with caution and considered as a starting point for further development of studies in this direction.

Future large-scale studies, such as GWAS, are needed to elucidate the molecular mechanisms of asthma and hypertension comorbidity; however, this will require large samples to evaluate the effects of genetic variants with moderate and small effects. 


\section{Acknowledgements}

This study was supported by the Volkswagen Stiftung Trilateral Partnerships - Cooperation Projects between Scholars and Scientists from Ukraine, Russia, and Germany "In silico screening and experimental validation of new drug targets for the treatment of co-morbid multifactorial diseases" (\# 90335). Project of the Integrated Basic Research Program of the SB RAS II.1 "Reconstruction, computer analysis and modelling of the structural and functional organization of biomedically significant gene networks" (\# 0324-2018-0021; \# 0550-2018-0003).

Conflict of Interest Statement: Authors state no conflict of interest. All authors have read the journal's Publication ethics and publication malpractice statement available at the journal's website and hereby confirm that they comply with all its parts applicable to the present scientific work.

\section{References}

[1] Divo M], Martinez CH, Mannino DM. Ageing and the epidemiology of multimorbidity. Eur Respir ] 2014;44:1055-68.

[2] Wahn U. What drives the allergic march? Allergy 2000;55:591-9.

[3] Anaya JM, Corena R, Castiblanco ], Rojas-Villarraga A, Shoenfeld Y. The kaleidoscope of autoimmunity: multiple autoimmune syndromes and familial autoimmunity. Expert Rev Clin Immunol 2007;3:623-35.

[4] Dzau V, Braunwald E. Resolved and unresolved issues in the prevention and treatment of coronary artery disease: a workshop consensus statement. Am Heart ] 1991;121:1244-63.

[5] Puzyrev VP, Freidin MB. Cenetic view on the phenomenon of combined diseases in man. Acta Naturae 2009;1:52-7.

[6] Dogra S, Ardern Cl, Baker ]. The relationship between age of asthma onset and cardiovascular disease in Canadians. ] Asthma 2007:44:849-54.

[7] Lee E], In KH, Ha ES, Lee K], Hur GY, Kang EH, et al. Asthma-like symptoms are increased in the metabolic syndrome. ] Asthma 2009;46:339-42.

[8] Johnson M, Nriagu ], Hammad A, Savoie K, Jamil H. Asthma, environmental risk factors, and hypertension among Arab Americans in metro Detroit. J Immigr Minor Health 2010;12:640-51.

[9] Lee HS, Park YM, Han K, Pekler G, Lee SS, Yoo S, et al. Sex-specific association between asthma and hypertension in nationally representative young Korean adults. Sci Rep 2017;7:15667.

[10] Onufrak S, Abramson ], Vaccarino V. Adult-onset asthma is associated with increased carotid atherosclerosis among women in the Atherosclerosis Risk in Communities (ARIC) study. Atherosclerosis 2007;195:129-37.

[11] Christiansen SC, Schatz M, Yang S], Ngor E, Chen W, Zuraw BL. Hypertension and asthma: a comorbid relationship. J Allergy Clin Immunol Pract 2016;4:76-81.

[12] Ferguson S, Teodorescu MC, Gangnon RE, Peterson AC, Consens FB, Chervin RD, et al. Factors associated with systemic hypertension in asthma. Lung 2014;192:675-83.

[13] Rzhetsky A, Wajngurt D, Park N, Zheng T. Probing genetic overlap among complex human phenotypes. Proc Natl Acad Sci USA 2007;104:11694-9.

[14] Goh KI, Cusick ME, Valle D, Childs B, Vidal M, Barabási AL. The human disease network. Proc Natl Acad Sci USA 2007;104:8685-90.

[15] Hamaneh MB, Yu YK. DeCoaD: determining correlations among diseases using protein interaction networks. BMC Res Notes $2015 ; 8: 226$.

[16] Saik OV, Demenkov PS, Ivanisenko TV, Bragina EY, Freidin MB, Goncharova IA, et al. Novel candidate genes important for asthma and hypertension comorbidity revealed from associative gene networks. BMC Med Cenomics 2018;11(Suppl 1):15.

[17] Ward LD, Kellis M. HaploReg: a resource for exploring chromatin states, conservation, and regulatory motif alterations within sets of genetically linked variants. Nucleic Acids Res 2012;40(Database issue):D930-4.

[18] Westra H], Peters M], Esko T, Yaghootkar H, Schurmann C, Kettunen ], et al. Systematic identification of trans eQTLs as putative drivers of known disease associations. Nat Cenet 2013;45:1238-43.

[19] Lappalainen T, Sammeth M, Friedländer MR, 't Hoen PA, Monlong ], Rivas MA, et al. Transcriptome and genome sequencing uncovers functional variation in humans. Nature 2013;501:506-11.

[20] GTEx Consortium. Human genomics. The Cenotype-Tissue Expression (GTEx) pilot analysis: multitissue gene regulation in humans Science 2015;348:648-60.

[21] Simpson ]L, Grissell TV, Douwes ], Scott R], Boyle M], Gibson PG. Innate immune activation in neutrophilic asthma and $\underline{\text { bronchiectasis }}$ Thorax 2007;62:211-8.

[22] Ferreira DS, Annoni R, Silva LF, Buttignol M, Santos AB, Medeiros MC, et al. Toll-like receptors 2, 3 and 4 and thymic stromal lymphopoietin expression in fatal asthma. Clin Exp Allergy 2012;42:1459-71.

[23] Zhang Q, Qian FH, Zhou LF, Wei CZ, Jin GF, Bai JL, et al. Polymorphisms in toll-like receptor 4 gene are associated with asthma severity but not susceptibility in a Chinese Han population. J Investig Allergol Clin Immunol 2011;21:370-7.

[24] Tizaoui K, Kaabachi W, Hamzaoui K, Hamzaoui A. Association of single nucleotide polymorphisms $\underline{\text { in }} \underline{\text { toll-like receptor genes with }}$ asthma risk: a systematic review and meta-analysis. Allergy Asthma Immunol Res 2015;7:130-40.

[25] Lau MY, Dharmage SC, Burgess ]A, Win AK, Lowe A], Lodge C, et al. The interaction between farming/rural environment and TLR2, TLR4, TLR6 and CD14 genetic polymorphisms in relation to early- and late-onset asthma. Sci Rep 2017;7:43681.

[26] Mansur AH, Bishop DT, Markham AF, Morton NE, Holgate ST, Morrison JF. Suggestive evidence for genetic linkage between IgE phenotypes and chromosome 14q markers. Am J Respir Crit Care Med 1999;159:1796-802. 
[27] Ober C, Tsalenko A, Parry R, Cox N]. A second-generation genomewide screen for asthma-susceptibility alleles in a founder population. Am J Hum Cenet 2000;67:1154-62.

[28] Malerba C, Patuzzo C, Trabetti E, Lauciello MC, Galavotti R, Pescollderungg L, et al. Chromosome 14 linkage analysis and mutation study of 2 serpin genes in allergic asthmatic families. J Allergy Clin Immunol 2001;107:654-8.

[29] Yuyama N, Davies DE, Akaiwa M, Matsui K, Hamasaki Y, Suminami Y, et al. Analysis of novel disease-related genes $\underline{\text { in }} \underline{\text { bronchial asthma. }}$ Cytokine 2002;19:287-96.

[30] Willer C], Schmidt EM, Sengupta S, Peloso GM, Gustafsson S, Kanoni S, et al. Discovery and refinement of loci associated with lipid levels. Nat Cenet 2013;45:1274-83.

[31] Teslovich TM, Musunuru K, Smith AV, Edmondson AC, Stylianou IM, Koseki M, et al. Biological, clinical and population relevance of 95 loci for blood lipids. Nature 2010;466:707-13.

[32] Locke AE, Kahali B, Berndt SI, Justice AE, Pers TH, Day FR, et al. Cenetic studies of body mass index yield new insights for obesity biology. Nature 2015;518:197-206.

[33] Dichgans M, Malik R, König IR, Rosand ], Clarke R, Gretarsdottir S, et al. Shared genetic susceptibility to ischemic stroke and coronary artery disease: a genome-wide analysis of common variants. Stroke 2014;45:24-36.

[34] Huan T, Esko T, Peters M], Pilling LC, Schramm K, Schurmann C, et al. A meta-analysis of gene expression signatures of blood pressure and hypertension. PLoS Cenet 2015;11:e1005035.

[35] Cheema AN, Rosenthal SL, llyas Kamboh M. Proficiency of data interpretation: identification of signaling SNPs/specific loci for coronary artery disease. Database (Oxford) 2017;2017. doi: 10.1093/database/bax078.

[36] Martinon F, Tschopp ]. Inflammatory caspases: linking an intracellular innate immune system to autoinflammatory diseases. Cell 2004;117:561-74.

[37] Lee Y, Schulte D], Shimada K, Chen S, Crother TR, Chiba N, et al. Interleukin-1 $\beta$ is crucial for the induction of coronary artery inflammation in a mouse model of Kawasaki disease. Circulation 2012;125:1542-50.

[38] Li S, Sheng ], Hu JK, Yu W, Kishikawa H, Hu MG, et al. Ribonuclease 4 protects neuron degeneration by promoting angiogenesis, neurogenesis, and neuronal survival under stress. Angiogenesis 2013;16:387-404.

[39] Tello-Montoliu A, Patel JV, Lip CY. Angiogenin: a review of the pathophysiology and potential clinical applications. ] Thromb Haemost 2006;4:1864-74.

[40] Marek-Trzonkowska N, Kwieczyńska A, Reiwer-Costomska M, Koliński T, Molisz A, Siebert ]. Arterial hypertension is characterized by imbalance of pro-angiogenic versus anti-angiogenic factors. PLoS One 2015;10:e0126190.

[41] Chetta A, Zanini A, Torre O, Olivieri D. Vascular remodelling and angiogenesis in asthma: morphological aspects and pharmacological modulation. Inflamm Allergy Drug Targets 2007;6:41-5.

[42] Abdel-Rahman AM, el-Sahrigy SA, Bakr SI. A comparative study of two angiogenic factors: vascular endothelial growth factor and angiogenin in induced sputum from asthmatic children in acute attack. Chest 2006;129:266-71.

[43] Zhou XF, Cui ], DeStefano AL, Chazaro I, Farrer LA, Manolis A], et al. Polymorphisms in the promoter region of catalase gene and essential hypertension. Dis Markers 2005;21:3-7.

[44] Hebert-Schuster M, Fabre EE, Nivet-Antoine V. Catalase polymorphisms and metabolic diseases. Curr Opin Clin Nutr Metab Care 2012;15:397-402.

[45] Polonikov AV, Ivanov VP, Solodilova MA, Kozhuhov MA, Panfilov VI. Tobacco smoking, fruit and vegetable intake modify association between -21A>T polymorphism of catalase gene and risk of bronchial asthma. J Asthma 2009:46:217-24.

[46] Kodydková ], Vávrová L, Kocík M, Žák A. Human catalase, its polymorphisms, regulation and changes of its activity in different diseases. Folia Biol (Praha) 2014;60:153-67.

[47] Zhou H, Polimanti R, Yang BZ, Wang Q, Han S, Sherva R, et al. Cenetic Risk Variants Associated With Comorbid Alcohol Dependence and Major Depression. JAMA Psychiatry 2017;74:1234-41.

[48] Edwards AC, Aliev F, Bierut L], Bucholz KK, Edenberg H, Hesselbrock V, et al. Cenome-wide association study of comorbid depressive syndrome and alcohol dependence. Psychiatr Genet 2012;22:31-41. 